\title{
THREE CASES OF FUR INFECTION OF THE CONJUNCTIVA FROM CATS.*
}

BY

ARNOLD LAWSON.

LONDON.

ALL three cases occurred in children whose parents were of the prosperous classes, and whose homes were therefore of the cleanest and best. I have never personally come across a similar case in an adult.

(1) My notes of this case, which occurred some years ago, are not satisfactory, as I have somehow lost that part of them which referred to the pathological examinations. The patient was a girl of 15 years, an only child, who somewhat lacking playmates, was devoted to a Persian cat. One evening shortly after having had an extra romp with the cat, during. which she had frequently buried her face in the cat's fur, in the way children are so fond of doing, her eyes became suffused and she also developed a bad sneezing fit. The next day her eyes and nose were swollen and discharge began to appear, and by the evening, when I first saw the child, the affection was acute. Both eyes were streaming with yellow purulent discharge and the lids were much chemosed. The nostrils were similarly greatly swollen, and purulent slightly sanguineous matter was freely oozing from them.

Cultures were taken of the discharge and also from the cat's fur. My recollection of the result, which, as stated, I have unfortunately lost from my case book, is that the staphylococcus pyogenes aureus was in abundance in the eye discharge, and that the same organism was isolated from the fur.

Energetic treatment on conventional lines soon effected improvement and the child eventually made an excellent recovery without any damage to the eyes.

It was for two or three days a source of great anxiety, as it was one of the most acute cases of purulent conjunctivitis that I have ever seen.

One has, of course, to be careful in such cases before definitely assigning the cause, but here there seemed no other possible explanation, as the child was living in the best of circumstances and was perfectly well until the cat episode occurred. I need scarcely add that the cat met with an untimely end.

(2) This case also occurred in a child of well-to-do people. The patient was a boy of 14 years of age and the case was an extremely complicated and severe one. The history was as follows.-About

* Read in the Section of Ophthalmology of the Royal Society of Medicine on February $7^{\text {th }}$, 1917 . 
a fortnight before I first saw the boy, a slight inflammation was noticed in the left eye, accompanied by slight discharge and a slight swelling over the left parotid. The local doctor thought that it was a case of mumps, and the boy was isolated. The swelling, however, did not run the course of mumps, and as it gradually grew larger and the conjunctivitis increased in spite of zinc lotion, the boy was sent up to me. There was during this fortnight no fever and no pain.

When I saw him, I noticed that the whole left side of the face was much swollen and that over the parotid there was a brawny induration not particularly tender, but with the skin slightly reddened over the angle of the jaw, extending into the neck, and almost continuous with the parotid swelling was another indurated mass evidently consisting of swollen glands. The lids of the left eye were considerably swollen, and eversion for examination was difficult. When this was effected, the conjunctival surfaces of both tarsi were seen to be fairly covered by coarse granulations, especially marked in the upper lid, where near the fornix were some bunches of exuberant granulation tissue. The retro-tarsal portions of both sacs were much chemosed with great enlargement of the follicles, and a fairly abundant muco-purulent discharge lay in the furrows of the swollen tissues. The bulbar conjunctiva was also considerably swollen and rather pink in colour. The cornea and all other structures were quite healthy.

The cause and nature of the trouble seemed at first obscure. Not unnaturally tubercle crossed my mind, but I dismissed it as improbable on account of the rapidity with which the disease had developed. There was further a history of a Persian cat of which the boy was very fond, and he was in the habit of walking about with it perched on his left shoulder; he cuddled it at irregular intervals. Systematic investigation was the only possible way at arriving at the causation and in the meantime the boy was put under an anæsthetic and the disease treated by thorough cutting and scraping, finishing up by thoroughly swabbing out the upper and lower sacs with a 2 per cent. solution of silver nitrate. The boy did very well and the glandular swellings at once began to subside. However, steady treatment for about six weeks with argyrol, weak copper drops, and an occasional touch of mitigated silver stick to spots where the granulations threatened to recur, was necessary before the boy was really well and the glands were not completely normal again for a little while longer still.

Now as to the investigation. The scrapings were put into sterile tubes and submitted immediately after operation to expert examination, and from them were isolated $(a)$ streptococcus longus, (b) streptococcus brevis, and (c) staphylococcus albus. Obviously the streptococcus was the important organism, and examination was directed to seeing if this could be found in the cat. The question 
arose as to whether any other animal but the cat was likely to be a factor, and as there was also a pet dog in the house (of which, however, the boy was not particularly fond), it was decided to examine both.

Portions of the hair and swabbings of the skin were taken in each case. The dog's hair revealed ( $a$ ) staphylococcus albus, $(b)$ bacillus subtilis, and (c) proteus vulgaris, whilst from the skin swabbing were obtained (1) staphylococcus aureus and albus, and (2) micrococcus catarrhalis. In the cat, the chief organism found in the hair was a staphylococcus albus, whilst in the skin swabbing a number of organisms were found, the most important being (a) streptococcus brevis and $(b)$ staphylococcus citreus, the other organisms consisting largely of bacillus proteus vulgaris and the bacillus subtilis.

It was, therefore, only in the case of the cat that an organism, a streptococcus similar to that found in the lid scrapings, was discovered. This fact, coupled with the history of the boy's fondness for the cat, gave the verdict unhesitatingly to the cat as the causative agent. The dog being found "not guilty" was acquitted, whilst the cat was summarily executed.

(3) This case was undoubtedly the worst of the three, for if the trouble had not been eradicated, it might undoubtedly have led to the child's death. It occurred in a little girl, aged five years. When staying with some friends of her parents in the country, where there was an adjacent farm, she contracted a muco-purulent conjunctivitis of a mild type. The history of its onset was that it supervened very shortly after nursing a cat which was a great favourite with her, and which divided its favours impartially between the child and the denizens of the neighbouring cowsheds. The conjunctivitis proved intractable to ordinary treatment, and she was taken to an expert for advice. Still, treatment did not improve matters, and after a time the submaxillary and sternomastoid glands on the same side began to enlarge. And so the case drifted on for two or three months, the eye apparently remaining in much the same condition of chronic mild conjunctivitis, and the neck trouble ever growing more formidable. Ultimately, I was called in to see the child, and on everting the upper lid, I found a mass of exuberant cock's-comb granulations occupying the greater part of the retrotarsal tissue and trespassing on the posterior edge of the tarsal plate. The lower sac was perfectly healthy except for a little reddening, and the trouble must have been discovered if anybody had everted the upper lid.

The clinical appearance combined with the history and enlargement of the cervical glands made one suspect that it was a case of conjunctival tubercle.

$I$ at once took the child into a nursing home, and under an 
anæsthetic, cut and scraped away all the infected parts ; finally, with due precautions, coated the whole operated surface with mitigated nitrate of silver stick. A certain amount of reaction followed as a matter of course, but warm boric bathings and pads, with the free use of weak iodoform ointment, answered very admirably, and the child made an excellent and complete recovery. I warned the parents that, if the glands in the neck were tuberculous and resultant on the conjunctival growth, the scraping and cutting away of the latter would probably be followed by an outburst of inflammation in the glands, and this is precisely what happened. Three little operations in the course of the next few months had to be performed on glands which in one case at any rate broke down, but ultimately the neck cleared up thoroughly well, and now, four years since the lid operation, the child is quite well without the slightest sign of recurrence either in the eye or glands.

The scrapings were submitted to Mr. S. H. Browning for examination. He reported that direct smears made from the ground-up scrapings showed the presence of a very few bacilli, which were very short and fat and resembled the bovine type of tubercle bacilli. Some of the scrapings were injected into the subcutaneous tissue of a guineapig, which rapidly wasted and died in a fortnight. The guinea-pig after death showed a small area of necrosis round the inoculation site with slight enlargement of the corresponding inguinal glands, but no other lesion. Microscopical examination from the local lesion and from the glands showed abundant tubercle bacilli. $\mathrm{Mr}$. Browning adds that "these tubercle bacilli were, in his opinion, of the bovine type, and the rapid death of the guinea-pig from the inoculation of extremely few bacilli (only five were found in twelve slides of the scrapings after prolonged search) tends to prove their bovine origin."

The guilt of the cat could unfortunately only be fixed by circumstantial evidence, because in spite of my best endeavours, I could never succeed in getting hold of it. The owners, indignant at the imputation cast upon their pet, and solicitous for its welfare, stoutly, and perhaps advisedly, refused to allow even an examination of its fur and skin. Still, I think the very great probability that the child was infected with the bovine type of tuberculosis, and the fact that the cat was a farm-yard cat and was a pet of the child who was continuously hugging and cuddling it, renders the ætiology of the case pretty clear and makes it fair to assume that the cat was the means by which the child was infected.

I have drawn the attention of the Section to these cases, not because there is anything specially new or interesting in them, for a fair number of similar fur infections of the eye already have been reported, but chiefly because I do not think the matter has been properly brought before the public, which does not sufficiently realize 
the danger of cats as a means of disseminating disease. The germcarrying guilt of rats, mice, flies and other noxious creatures, which are in themselves a nuisance and are generally hated, has been cordially recognised and means to deal with them by extermination are eagerly welcomed, but although I believe the cat is as bad an enemy in this way as any animal or insect, I fear that any attempt to exterminate these wandering nocturnal curses would meet with a hopeless opposition. I think the public, as a body, still believes in the fallacy of the cat being more cleanly than most other species of animals, and yet quotes the argument of the free use of its tongue and saliva on its fur to clinch the subject; and so, I fancy, the only thing to do is to impress more forcibly the fact that the cat, as a pet, is a source of danger chiefly to children who naturally love to cuddle it and to bury their head and faces in its septic fur.

\section{ABSTRACTS.}

I.-OPERATIONS.

(First Notice.)

I.-Cataract.

(I) Starkey, Horace M. (Rockford).-Report of case ot expulsive retrochoroidal hæmorrhage following cataract extraction. Ophthalmology, April, 1915.

(2) Burnham, G. H. (Toronto).-Some unusual features in the case of a senile cataract extraction. Ophthalmic Record, October, 1915.

(3) Heyl (Munich).-Statistics about cataract operations with special consideration of the relationship between ripeness of the cataract and secondary cataract. (Statistik über Staroperationen mit besonderer Berucksichtigung der Beziehungen $z$ wischen Reife des Stars und Häufigkeit des Nachstars.) Archiv für Augenheilkunde, Bd. LXXVIII, I915, S. 239.

(4) Bruns, Henry Dickson (New Orleans). - The ambulant after-treatment of cataract extraction; with a note on post-operative delirium and on striped keratitis. Trans. Amer. Ophth. Society, Vol. XIV, Part ii, p. 473, I9I6.

(5) Wheeler, John M. (New York City).-A study of hæmorrhage into the anterior chamber, subsequent to operations for hard cataract. Trans. Amer. Ophth. Society, Vol. XIV, Part ii, p. 742, 1916. 